\title{
CORRIGENDUM
}

\section{Fine bakery wares with label claims in Europe and their categorisation by nutrient profiling models}

\author{
J Trichterborn, G Harzer and C Kunz \\ European Journal of Clinical Nutrition (2012) 66, 280; doi:10.1038/ejcn.2011.172
}

Correction to: European Journal of Clinical Nutrition (2011) 65, 307-312; doi:10.1038/ejcn.2010.275

Since the publication of this paper, the authors have been made aware that 'SAIN,LIM' is the correct spelling of one of the nutrient profiling models mentioned in the study. In addition, the most recent version of the model contains 5 basic and 4 optional positive nutrient criteria and not 15 as mentioned in the text and in Table 1 (Darmon et al., 2009). The corrected Table 1 and the corresponding reference to the model are shown below. These errors do not have any impact on the results of the study, as the positive criteria were not applied.
The authors would like to apologise for any inconvenience caused.

\section{Reference \\ Darmon N, Vieux F, Maillot M, Volatier JL, Martin A (2009). Nutrient profiles discriminate between foods according to their contri- bution to nutritionally adequate diets: a validation study using linear programming and the SAIN,LIM system. Am J Clin Nutr 89, $1227-1236$.}

Table 1 Overview of chosen nutrient profiling models and their key parameters

\begin{tabular}{|c|c|c|c|c|c|}
\hline & Choices Programme & Smart Choices Program & FSA/OFCOM & SAIN,LIM & $F D A$ \\
\hline Objective of current use & $\mathrm{FOP}^{\mathrm{a}}$ & $\mathrm{FOP}^{\mathrm{a}}$ & $A D V^{b}$ & $C L^{\mathrm{c}, \mathrm{d}, \mathrm{e}}$ & $\mathrm{CL}^{\mathrm{c}}$ \\
\hline Number of (sub)categories & $1+22$ & $1+19$ & $1^{f}$ & 1 & 1 \\
\hline Calculation approach & $\mathrm{T}$ & $\mathrm{T}$ & $\mathrm{S}$ & $\mathrm{S}$ & $\mathrm{T}$ \\
\hline Number of nutrients (negative/positive) & $(4 / 1)$ & (6/1 out of 7$)$ & $(4 / 3)$ & $(3 / 5+4)$ & (4/1 out of 6$)$ \\
\hline Reference value & $100 \mathrm{~g} / \mathrm{kcal}$ & One serving $/ 100 \mathrm{kcal}$ & $100 \mathrm{~g}$ & $100 \mathrm{~g} / \mathrm{kcal}$ & One serving \\
\hline
\end{tabular}

Abbreviations: ADV, advertising; CL, claims; FDA, Food and Drug Administration; FOP, front-of-pack; FSA, Food Standards Agency; S, scoring; T, threshold.

apositive front-of-pack signposting.

${ }^{\mathrm{b}}$ Advertising regulations.

'Claims regulation.

dProposed for this purpose.

e In this study, only the LIM criteria could be applied (see Results).

${ }^{f}$ Model distinguishes between foods and drinks. 